\title{
Under which conditions does ICT have a positive effect on teaching and learning? A Call to Action
}

\author{
J. Voogt,* G. Knezek,† M. Cox,‡ D. Knezek§ \& A. ten Brummelhuisף \\ *Department of Curriculum Design and Educational Innovation, University of Twente, Enschede, the Netherlands \\ tDepartment of Learning Technologies, University of North Texas, Denton, TX, USA \\ ¥King's College London, London, UK \\ §International Society of Technology in Education, Washington DC, USA \\ IKennisnet, Zoetermeer, the Netherlands
}

\begin{abstract}
'Under which conditions does ICT have a positive effect on teaching and learning?' This was the leading question of the International EDUsummIT in The Hague, the Netherlands. The bases for the discussion were the scholarly findings of the International Handbook of Information Technology in Primary and Secondary Education, a synthesis of research in the field of information and communication technology (ICT) in education. Seventy international policymakers, researchers, and practitioners developed a Call to Action, which summarizes the main action points where policy, research, and leadership need to join forces in order to successfully implement ICT in educational practice. These main action points include a view on the role of ICT in 21st century learning; conditions for realizing the potential of multiple technologies to address individual needs of students; better understanding of the relationship between formal and informal learning; the implications of technology for student assessment; the need for models for leadership and teacher learning to successfully implement technology; the potential of ICT for digital equity; and the development of a list of essential conditions to ensure benefit from ICT investments. In this contribution, we present the Call to Action and synthesize the research on which the Call is based.
\end{abstract}

Keywords Call to Action, ICT integration, primary education, research synthesis, secondary education.

\section{Introduction}

The learning landscape is undergoing fundamental changes, requiring new methods and perspectives to capture the new capabilities and learning processes that have emerged because of the basic technology infrastructure and tools generally available and the augmented capabilities that learners have through the use of such tools. These observations brought together

Accepted: 24 August 2011

Correspondence: Joke Voogt, Department of Curriculum Design and Educational Innovation, University of Twente, P.O. Box 217, 7500AE Enschede, the Netherlands. Email: j.m.voogt@utwente.nl approximately 70 leading researchers, policymakers, and practitioners spanning six continents. They gathered in The Hague in 2009 at an international conference designed to define action steps following the publication of the Handbook on ICT in Primary and Secondary Education (Voogt \& Knezek 2008). In a number of consecutive sessions, issues about how to formulate and implement an agenda aiming to stimulate the use of ICT in primary and secondary education were discussed, resulting in a Call to Action (see also http:// www.edusummit.nl). In this paper, we discuss this agenda for change from the perspective of the central question that guided the EDUsummIT 'Under which 
conditions does ICT have a positive effect on teaching and learning?'

\section{A Call to Action}

\section{Teaching and learning processes}

Four actions are called for which concern teaching and learning processes. They deal with the relationship between (1) ICT and 21st century learning; (2) restructuring schools to be able to use technology in addressing individual needs of students; (3) the need for new assessment structures to be able to measure outcomes of technology-rich experiences; and (4) the relationship between formal and informal learning experiences and its implications for formal learning.

Action 1: To establish a clear view on the role of ICT in 21 st century learning and its implications for formal and informal learning

A better understanding is needed about ICT's role in 21 st century learning, especially in relation to the formal and informal settings where 21st century skills may be acquired. Policymakers, leaders and researchers need to work closely together to incorporate $21 \mathrm{st}$ century skills in curricula and to develop assessments of those skills.

Voogt $(2003,2008)$ argued that 21 st century skills, as an educational goal, align with developments in the learning sciences (see, for example, Bransford et al. 2000) about the importance of learner-centred instruction to enhance student learning. She projected pedagogical approaches that are consistent with the expectations and values of the knowledge society and showed how these might differ from those consistent with the expectations and values of the industrial society. According to her, the pedagogical approaches that are expected to be important in the knowledge society should include, among others, providing variety in learning activities, offering opportunities for students to learn at their own pace, encouraging collaborative work, focusing on problem solving, and involving students in the assessment of their learning. This implies that not only is there a need for 21 st century skills but also that these skills ask for learner-centred approaches to education, which might be referred to as 21 st century learning.

It is without question that ICT has a primary place in 21 st century skills and 21 st century learning. The acquisition of ICT skills is therefore not only an educational goal, but ICT also serves as a tool to support teaching and learning.

Voogt and Pareja Roblin (2010) analysed different frameworks that elaborated more in depth what $21 \mathrm{st}$ century skills encompass. All these frameworks referred to domains of what Anderson (2008) called 'applied ICT literacy', namely: a technical domain (related to the basic skills needed to use ICT), a knowledge domain (which refers to the use of ICT with a particular knowledge-related purpose), and an information literacy domain (related to the capacity to access, evaluate, and use information). Applied ICT literacy is perceived important by researchers and policymakers; however, it is not easily incorporated in educational practice. Law (2009) found in an international study of grade 8 science and mathematics teachers that teachers' pedagogical orientations, as well as their students' practices, were not very much oriented towards 21 st century learning. However, when ICT was involved, students' practices seemed a little more directed towards 21 st century learning. A more positive finding was found by Voogt and Pelgrum (2005). They conducted a systematic analysis of an international set of ICT-supported innovative educational practices and showed that the acquisition of 'applied ICT literacy' was often an integrated part in pedagogical practices in which also other 21 st century skills were addressed. The pedagogical practices in their study however were selected because of their innovativeness. Law et al. (2010) observed a shrinking orientation towards 21 st century learning of teachers in some European countries, and a growing orientation in some Asian countries, when comparing data from 1997 with data from 2006. Their inference was that changes in national educational policies had an impact on teachers' orientation towards 21 st century learning. Policymakers, leaders, and researchers need to work closely together to incorporate 21 st century skills in curricula, including the utilization of ICT as a learning tool and as a learning goal.

Action 2: To develop new assessments designed to measure outcomes from technology enriched learning experiences

In many countries ICT has become an integrated part of curricular frameworks in primary and secondary education. However, assessment frameworks are often not changed accordingly. An urgent need for alternative assessment approaches and instruments is indicated, along with an understanding of the impact of IT on assessment. 
The call for alternative assessment frameworks in order to understand the impact of ICT on teaching and learning is closely related to the need for 21 st century learning. On the one hand, ICT is often used to support the acquisition of 21 st century skills; on the other hand, there is also a need to determine students' acquisition of 'applied ICT literacy' (Anderson 2008). An important problem in establishing students' attainments in 21st century skills, including their ICT skills, is that these types of skills cannot easily be determined by means of simple, standardized tests. The complexity of the problem can for instance be illustrated by experiences in the Computer as a Learning Partner (CLP) project. CLP was a predecessor of the Web-based Inquiry Science Environment project (Linn \& Hsi 2000). In the CLP project, students did science inquiry learning in an ICTrich learning environment. Research findings showed that students involved in CLP did not score better on multiple-choice items in standardized tests that required recall, but they outperformed students on items that required interpretation. Yet, the outcomes of CLP had much more impact on student learning than could be determined in standardized tests. CLP could demonstrate that comparing subsequent versions of the ICTrich curriculum for science education resulted in a $400 \%$ increase - over eight versions of the curriculum in student understanding of the complex science concepts that were dealt with in the curriculum. This example shows that other tests are needed when 21st century skills are at stake. Several researchers (e.g. Erstad 2008; Quellmaz 2009) advocate the development of performance assessment for testing complex cognitive skills. In performance testing, students perform a task instead of ticking an option from several alternatives. However, when the aim of testing is to get a highly valid and reliable estimate of students' attainment for accountability or selection purposes, it is not easy to design performance assessments that meet these quality requirements, and can be used for larger scale testing. Some recent initiatives study how performance assessments can be designed in order to meet the usual psychometric quality criteria. Clarke (2009) started a study to develop and test virtual performance assessments for science inquiry learning that meet the criteria of reliability and validity. Another recent initiative is the International Association for the Evaluation of Educational Achievement (IEA) International Computer and Information Literacy Study (Fraillon \& Ainley 2010), which plans to assess students' ICT literacy across countries through computer-based authentic tasks. In this study, ICT is not only considered the object of assessment - assessing ICT literacy skills - but also a tool to support the assessment itself. The findings of the aforementioned initiatives will not only contribute to a better understanding of the potential of performance assessment for assessing 21 st century skills but also of the potential of ICT in such assessments.

For successful implementation of 21 st century skills, including ICT literacy skills, not only strategies for summative assessment are needed but also for formative assessment. Webb (2008), when discussing the impact of ICT in science education, argues that, because of the affordances of ICT, students get a more in-depth understanding of complex science concepts. Formative assessment is needed to inform students and teachers about how students' understanding of these concepts develop, so that learning needs can be identified and, with the help of the teacher, appropriate planning of useful learning activities can be developed. In the E-scape project (Goldsmiths 2009), handheld technology is used to enable students to build an online portfolio of their performance, demonstrating their capability as it emerges. The project studies the potential of the technology both for formative and summative assessment purposes.

Action 3: To radically restructure schools to be able to use multiple technology-enhanced pedagogies to address individual needs of students

Integrated research and development of infrastructure (mobile technologies), digital content and pedagogies are needed to better prepare schools to use technology enhanced pedagogies to benefit student learning.

From the perspective of 21 st century learning, the implementation of ICT is part of a comprehensive change of the education system. International policy initiatives that advocate 21st century skills [e.g. from European Union (EU) and United Nations Educational, Scientific and Cultural Organization] notice that to realize these goals an in-depth transformation of the school system might be the ultimate consequence (Voogt \& Pareja Roblin 2010). Dede (2010b) argues that implementing 21 st century skills and 21 st century learning is a challenge for the current curriculum, because the change that is being asked for is not about trading 20th century content and goals for those of the 21 st century; it is about what has to be core in the 21 st 
century curriculum and about the implications of a 21 st century curriculum for the current school system. According to Dede (2010a), this discussion is not a rational discussion only, but also has to do with the unlearning of beliefs, values, assumptions, and perceptions on school culture that researchers, practitioners, and policymakers hold about the current school system. Venezky (2004), based on an international study about school-wide use of ICT, found that the implementation of ICT in schools does not automatically lead to a structural change of the current school system. According to Venezky, ICT can be seen as a lever for educational change, but this lever has to be put into action by the school community and needs to be based on a shared vision and shared goals. Findings from IEA's Second International Technology in Education Study (Voogt \& Pelgrum 2005) showed that only a minority of the innovative ICT-supported pedagogical practices (6\%) reflected school-wide use of ICT. These schools all had a strong emphasis on students' independence and responsibility for their own learning and had restructured their school to realize that vision. The use of ICT was vital in the new structure and had become a routine throughout the school. The teachers in these schools reported that in order to transform their school, teacher collaboration and teacher learning were crucial and had become an integrated part of the school's culture (Voogt $\&$ Pelgrum 2005). School-wide integration of ICT was also found by Eickelmann (2010) as one of the factors that fosters sustainable ICT implementation. Other factors were a strong connection between pedagogical aims and ICT, strong leadership, school-wide adoption of ICT, a focus on the process, collaboration with external partners (also from the private sector) and with other schools (to share ideas and approaches), and being able to cope with new trends.

Action 4: To better understand student technology experiences in informal learning environments, in order to inform work in formal settings

Research is needed to better understand the implications of immersion in technology-rich informal learning environments. Policy makers and leadership need to develop policies and actions on the implications of such informal learning environments for formal learning settings.

It is often assumed that through the overall presence of ICT, students automatically are immersed with technology, and that special attention for ICT in the curriculum as a tool and as an object for learning is not necessary. For instance, Prensky (2001) talks about digital immigrants and digital natives. Digital immigrants experience ICT as a phenomenon, alien to their life; while for those who grew up with technology, the digital natives, technology fundamentally impacts their way of learning and living. Digital natives 'think and process information fundamentally differently' (Prensky 2001). However, recent research shows big differences between students' knowledge and use of technology (Bennett \& Maton 2010; Kennedy et al. 2010), let alone in their use of technology for learning.

\section{Teachers and schools}

There is general agreement that active involvement of teachers and schools is key to the implementation of ICT in educational practice. Two actions were called for related to (1) teacher preparation and teacher learning for technology implementation; and (2) the facilitating role of schools in making technology integration happen.

\section{Action 5: To develop and use models for teacher learning on technology use in schools and classrooms at the pre- and in-service levels \\ Policy needs to be developed on levels of knowledge responsibility and capacity of teachers in ICT integra- tion. Further research and development of models such as the TPaCK (Technological Pedagogical Content Knowl- edge) model is indicated in relation to the development of collaborative models for teacher learning on ICT integra- tion, at the pre- and in-service levels.}

The adoption of technology by teachers is conceived as a process that develops through different stages: from being aware and informed about the possibilities of ICT in education, to a more routine utilization of ICT in classroom practice, and finally to creative uses of technology for teaching and learning (Sandholtz et al. 1997; Christensen \& Knezek 2008). To be able to predict teachers' adoption of technology, Christensen and Knezek (2008) developed an empirically tested model in which three constructs - teachers' attitude (as an expression of 'will'), their competencies (as an expression of their 'skill'), and their access to technology predict their adoption of technology. Knezek and Christensen (2008) used self-report measures to measure competencies, which in fact measure teachers' confidence in using computers for teaching and learning purposes and can be considered a self-efficacy measure 
(Bandura 1977). Christensen and Knezek found that ICT competencies and access to technology are important during the first stages of technology adoption. While in the 21 st century, access to technology is no longer a problem in most of the USA, it still is in countries like Mexico (Morales 2006). In addition to these findings, Knezek and Christensen also found that teachers who use ICT creatively had a highly positive attitude towards ICT. In addition, although many teachers possess basic ICT competencies, many of them lack competencies related to the pedagogical use of ICT (e.g. Law et al. 2008). Based on the need to be able to integrate technology skills with pedagogical skills in order to successfully integrate ICT in educational practice, Koehler and Mishra $(2005,2008)$ elaborated the TPACK model. TPACK stands for technological pedagogical content knowledge and is related to Shulmans' notion of pedagogical content knowledge (PCK) (Shulman 1987). PCK represents the unique expertise teachers have. By blending pedagogical and disciplinebased knowledge, teachers are able to teach complex concepts. Through adding technology to PCK, teachers should become aware that in today's teaching, technology has an indispensable role, because it can add to the pedagogy as well as to the content of many subjects. The TPACK model seems to be a powerful model to further understand the knowledge teachers need to integrate ICT in their teaching. Voogt et al. (2010) conducted a systematic literature review on TPACK which showed that the empirical underpinning of the model is still in its infancy. More research is needed about (1) typical TPACK competencies for different subject matter domains; (2) assessment of teachers' TPACK competencies; and (3) strategies for learning TPACK competencies by practicing and prospective teachers. Voogt et al. (2010) also argued that further development of TPACK might benefit from research on teacher professional development and on research about students' use of ICT in subject matter domains.

Several researchers argue that TPACK is not enough to enhance the integration of ICT in educational practice. Research on teachers' beliefs about teaching and learning show the relationship between teachers' beliefs and their use of technology in the classroom (Niederhauser \& Stoddart 2001; Ertmer 2005; Tondeur et al. 2008). Voogt (2010) found that frequency of ICT use and a pedagogical orientation on 21 st century learning are positively related. Similar findings were found by
Tondeur et al. (2008). Law (2008) argues that teachers need to develop competencies to enact change. In her view, technology has the potential to transform schools, and teachers need to be able to actively participate in that process. Drent and Meelissen (2008) and Riel and Becker (2008) point teachers' professional identity. Those teachers who see themselves as 'entrepreneurs' (Drent \& Meelissen) or take leadership roles (Riel \& Becker) are more likely to use ICT in creative ways than other teachers.

Action 6: To develop and use distributed leadership models for technology use in schools and teacher education programs

An ecological perspective is needed to study ICT use in classrooms, in order to help explain and influence the complex interactions and events. Such a perspective benefits from distributed leadership models supported by information and communication technology (ICT) to help engage people at different levels of the ecology to effect change that flows throughout the system.

Teachers function not in isolation, but as part of a socio-cultural environment that encourages or inhibits the use of ICT (Somekh 2008). According to Davis (2008), this socio-cultural environment can be understood as the ecology of school renewal. This ecology exists of multiple overlapping and interacting layers which impact the utilization of ICT in the classroom. Davis argues that teachers and schools need to understand this ecology to be able to provide leadership in ICT implementation. Successful ICT leadership should not be assigned to an individual, but needs to be distributed (Bennett 2008; Dexter 2008). Distributed leadership implies that leadership is the property of a group and not of a single person and that expertise is distributed among many and not among a few (Bennett 2008). In a study of US schools, Anderson and Dexter (2005) found that ICT responsibilities are often shared between the principal, a technology coordinator, and teacher leaders. According to Dexter (2008), ICT leadership can be successful when school leadership sets clear learning goals that can be accomplished with the help of technology, puts in place an ICT support system, and creates a learning environment for teachers to develop teachers' TPACK competencies. Such an environment, as a way to organize teachers' professional learning, should be an integrated part of a collaborative culture in schools, supported by the leadership (McLaughlin \& Talbert 2001). Further research is needed to better understand the relationship between 
the ecology of school renewal, distributed leadership and ICT implementation, as well as the particular role of teacher leaders in ICT implementation with regard to both their leadership and their teaching role.

\section{Policy for equity and practice}

Policy can facilitate or hamper the implementation of ICT and can also provide directions for ICT integration. Two actions were called for related to (1) the implementation of ICT and digital equity; and (2) a list of necessary conditions at the policy level for ICT implementation.

Action 7: To develop ideas on international opportunities relating to new and emerging technologies in order to address the needs of developing countries and promote global social awareness and responsibilities

Students around the globe are entitled to access to technology to enhance their opportunities for learning. The sponsoring organizations commit themselves to put this concern of EDUsummIT participants on the agenda of international organizations such as UNESCO and the EU.

Figures about access to computers are only partially informative with respect to how computers can be used in educational practice. Based on a secondary analysis of data from the Organisation for Economic Cooperation and Development Programme for International Student Assessment study, Ainley et al. (2008) made clear that contexts for IT access and uses differ among countries. Norris and Soloway (2008) argue that the emergence of low-cost mobile computing devices contributes to access to technology on a global scale, in particular, the widespread use of cell phones (Brown 2008), and initiatives, such as the One Laptop Per Child project. However, access to technology is not the only aspect of digital equity. Gibson (2008) therefore emphasizes the importance of 'doing equity' for realizing digital and social equity goals through collaborative projects with students from different parts of the world or different socio-economic backgrounds. A study from Roy et al. (2008) showed how availability and access to content in local languages can support minority societies to survive in the majority society.

Resta and Laferrière (2008) proposed five dimensions that are relevant for realizing digital equity: (1) access to hardware, software, and connectivity to the Internet; (2) access to meaningful, high quality, cultur- ally relevant content in local languages; (3) access to creating, sharing, and exchanging digital content; (4) access to educators who know how to use digital tools and resources; and (5) access to high quality research on the application of digital technologies to enhance learning. To ensure digital equity, these dimensions should be considered in any general policy on ICT in education.

Action 8: To develop and disseminate a list of essential conditions which need to be in place to ensure benefit from technology investments

The investments of ICT in education are often not reflected in expected benefits. Policy makers around the world can learn from the mistakes related to ICT policy in the past.

Several researchers (Kozma 2008; Moonen 2008; Tilya 2008) identified elements of strategic and operational policies that need to be in place for implementation of ICT to be beneficial for education. Kozma (2008) observed four rationales that guide the strategic policies for ICT in education: (1) support economic growth; (2) promote social development; (3) advance educational reform; and (4) support education management. Often, more than one rationale can be found in policy documents. However, for policy to be effective, operational policies need to be defined in place, including a timeline, an appropriate budget, and an organizational structure aiming at the implementation in practice (Moonen 2008). Kozma (2008) emphasized the need for alignment of strategic and operational policies. Tilya (2008) and Kozma (2008) both mention crucial elements of operational policies. A combination of their lists is presented here and can act as the start of a list of essential conditions that need to be in place in order to benefit from technology investments.

- Infrastructure development: Particularly in developing countries, it is important that policy helps schools to have a minimum acceptable infrastructure at their disposition. The infrastructure not only consists of hardware, software, and network resources but also includes electricity, phone lines, insurance, and safe and secure school buildings (Tilya 2008). Infrastructure policies need to take care of equality of access to hardware and software (Kozma 2008; Resta \& Laferrière 2008). The potential of mobile technologies to address the problem of unequal access to hardware (Norris \& Soloway 2008) needs to be taken into 
account when developing operational policies addressing ICT infrastructure. Schools need guidelines on how to set up their own ICT infrastructure in relation to their educational vision.

- Teacher professional development: Plans are needed to support teachers in the development of ICT skills. As has been argued earlier, teachers not only need to have basic ICT literacy skills; they also need to learn how to use ICT in pedagogical settings and how to integrate ICT in the curriculum. Conventional coursebased training programmes lack follow-up support at the workplace (Joyce \& Showers 1995) and have therefore proven not to be very useful. For professional development to be effective, it needs to (1) focus on translating general ideas into concrete classroom applications; (2) expose teachers to actual practice rather than descriptions; (3) provide opportunities for group support and collaboration; and (4) involve deliberate evaluation and feedback by skilled practitioners (Elmore \& Burney 1999). For this reason, operational policies aiming at teacher professional development should also include provisions to realize support at school level.

- Support: The rapid technological developments require a quite sophisticated support structure. Policy therefore needs to provide for ongoing technical, human, and organizational support. Technical support has to do with keeping the infrastructure up to a certain standard. Teachers need support in keeping up to date with the potential of hardware and software for teaching and learning. Such support should be related to provisions for teacher professional development at school level (Strudler \& Haerrington 2008). Organizational support deals with the organization and distribution of access to ICT in schools. The organization of support is a complex effort for many schools. Schools need to decide whether they should invest in support personnel and/or whether they should outsource parts of the support to external parties. Policy can facilitate ICT implementation when wellelaborated provisions and guidelines for ICT support are in place, including exemplary task descriptions for ICT coordinators.

- Articulation of ICT-related changes in curriculum: The added value of ICT lies in the way ICT supports teaching and learning. Successful implementation of ICT requires the development of policy frameworks to align the changes that are needed in curriculum, pedagogy, and assessment due to the implementation of ICT.

- Content development and management: As Resta and Laferrière (2008) already stated, content appropriate for the local context is needed. This may imply the development of digital content in local languages or reflecting local culture (Kozma 2008). In addition, the development of such content needs to be made accessible for teaching and learning. Policy should be in place to support these developments.

- Continuous evaluation and research: Investments in ICT are huge. For this reason, monitoring the effect of ICT policies should be an integral part of any ICT policy. There is a need to have a set of indicators to provide a better insight of the impact of ICT on education. Pelgrum (2009) carried out a study among countries in the EU about indicators on ICT in education. He found that particularly a need was expressed for indicators about (1) opportunities to learn with and/or about ICT; (2) competencies and attitudes of students; (3) ICT support; (4) teacher training; and (5) school leadership. Pelgrum also found that in some existing assessments indicators are used that have exceeded their lifetime (for instance by using the term computer, while a range of digital devices are implied). Pelgrum advocates shifting the emphasis in monitoring from ICT-related conditions to ICT-related student-outcomes. However, as the International Handbook of Information Technology in Primary and Secondary Education has showed (Voogt \& Knezek 2008), research is able to show the potential of ICT, but ongoing research about the conditions under which this potential can best be realized is urgently needed.

- Private-public partnerships: Widespread use of ICT is expensive for any country. Partnerships between the educational community and the private sector might therefore serve as an additional resource for education (Kozma 2008; Tilya 2008). Policy guidelines are needed to frame public-private partnerships to prevent education from losing its independence.

\section{From action to implementation}

This paper started with the question 'Under which conditions does ICT have a positive effect on teaching and learning?' Eight actions are proposed to join forces in order to realize successful implementation of ICT in 
education. Findings from research are provided to inform the reason for these actions. These actions together should form the agenda of policy, research, and practice. In addition to these eight actions, actions have also been developed to facilitate the process of implementation of the joint agenda. These actions are briefly described and explained below.

- To actively study both research on and development of ICT applications in classrooms.

- To use findings presented in the Handbook to inform research, policy, and leadership for ICT in schools.

- To develop mechanisms for sharing and distributing research, promising policies, and practices on ICT in education.

- To nurture an international community of ICT scholars, policymakers, and leaders who continually build upon our knowledge base to inform policy and practice.

- To disseminate and discuss the recommendation in this Call to Action to other national and international ICT initiatives.

The use of scientific research for educational practice has been the topic of many debates in education (e.g. Geddis et al. 1998; Cochran-Smith \& Lytle 1999; Badley 2003; Levin 2004; Newman \& Cole 2004). Practitioners have doubts about the value of research for their practice, while researchers are dissatisfied about the unwillingness of practitioners to utilize findings from research. De Vries and Pieters (2007) advocate therefore the use of new forms of cooperation between researchers and practitioners, such as design research (Van den Akker et al. 2006; Reeves 2008) and action research (Elliott 1991; Cochran-Smith \& Lytle 2009). These research approaches are grounded on collaboration between researchers and practitioners, and practitioner-driven research agendas are assumed. Networks and connections between practitioners and researchers need to be developed in order to contribute to shared knowledge development. The promotion of such research approaches requires that researchers who work with practitioners in order to develop implications for practitioners are recognized in scientific publications. Review processes of scientific journals need to include a review of the implications of the research for practice. Developments of ICT in education call for a regular update of the International Handbook of Infor- mation Technology in Primary and Secondary Education and for the identification of emerging research themes to be addressed. To realize this, the creation of an infrastructure (e.g. through social media) is indicated, so that results of scientific research can be shared with a large audience.

The EDUsummIT was held in 2009 and caused a number of presentations and discussions at professional and scientific conferences. A second EDUsummIT is planned for 2011. Its focus will be on reviewing and updating the current Call to Action by bringing together groups from different disciplines and leaders from around the world to foster cross-pollination and to address issues of leadership and practice with and through technology.

\section{Acknowledgements}

The authors wish to thank Kennisnet (the Netherlands), BECTA(UK), and ISTE (USA) for organizing the International EdusummIT.

\section{References}

Ainley J., Enger L. \& Searle D. (2008) Students in a digital age: implications of ICT for teaching and learning. In International Handbook of Information Technology in Primary and Secondary Education (eds J. Voogt \& G. Knezek), pp. 63-80. Springer, New York, NY.

Anderson R. (2008) Implications of the information and knowledge society for education. In International Handbook of Information Technology in Primary and Secondary Education (eds J. Voogt \& G. Knezek), pp. 5-22. Springer, New York, NY.

Anderson R. \& Dexter S. (2005) School technology leadership: an empirical investigation of prevalence and effect. Educational Administration Quarterly 41, 49-82.

Badley G. (2003) The crisis in educational research: a pragmatic approach. European Educational Research Journal 2, 296-308.

Bandura A. (1977) Self-efficacy: toward a unifying theory of behavioral change. Psychological Review 84, 191-215.

Bennett N. (2008) Distributed leadership and IT. In International Handbook of Information Technology in Primary and Secondary Education (eds J. Voogt \& G. Knezek), pp. 597-613. Springer, New York, NY.

Bennett S. \& Maton K. (2010) Beyond the digital natives debate: towards a more nuanced understanding of students' technology experiences. Journal of Computer Assisted Learning 26, 321-331. 
Bransford J.D., Brown A.L. \& Cocking R.R., eds (2000) How People Learn. Brain, Mind, Experience, and School. Expanded Edition. National Academy Press, Washington, DC.

Brown T.H. (2008) M-learning in Africa: doing the unthinkable and reaching the unreachable. In International Handbook of Information Technology in Primary and Secondary Education (eds J. Voogt \& G. Knezek), pp. 861-872. Springer, New York, NY.

Christensen R. \& Knezek G. (2008) Self-report measures and findings for information technology attitudes and competencies. In International Handbook of Information Technology in Primary and Secondary Education (eds J. Voogt \& G. Knezek), pp. 397-417. Springer, New York, NY.

Clarke J. (2009) Studying the potential of virtual performance assessments for measuring student achievement in science. Paper presented at the American Educational Research Association, San Diego, April 13-17.

Cochran-Smith M. \& Lytle S. (2009) Teacher research as stance. In The SAGE Handbook of Educational Action Research (eds S. Noffke \& B. Somekh), pp. 39-47. Sage, London.

Cochran-Smith M. \& Lytle S.L. (1999) Relationships of knowledge and practice: teacher learning in communities. Review of Educational Research 24, 249-305.

Davis N. (2008) How may teacher learning be promoted for educational renewal with IT? In International Handbook of Information Technology in Primary and Secondary Education (eds J. Voogt \& G. Knezek), pp. 507-519. Springer, New York, NY.

Dede C. (2010a) Technological supports for acquiring $21^{\text {st }}$ century skills. In International Encyclopedia of Education, 3rd edition (eds E. Baker, B. McGaw \& P. Peterson), pp. 158-166. Elsevier, Oxford, England. Available at: http:// learningcenter.nsta.org/products/symposia_seminars/iste/ files/Technological_Support_for_21stCentury_Encyclo_ dede.pdf (last accessed 10 January 2010).

Dede C. (2010b) Comparing frameworks for 21st century skills. In 21 st Century Skills (eds J. Bellanca \& R. Brandt), pp. 51-76. Solution Tree Press, Bloomington, IN.

De Vries B. \& Pieters J.M. (2007) Bridging the gap between research and practice: exploring the role of knowledge communities in educational change. European Educational Research Journal 6, 382-392.

Dexter S. (2008) Leadership for IT in schools. In International Handbook of Information Technology in Primary and Secondary Education (eds J. Voogt \& G. Knezek), pp. 543554. Springer, New York, NY.

Drent M. \& Meelissen M. (2008) Which factors obstruct or stimulate teacher educators to use ICT innovatively. Computers and Education 51, 187-199.
Eickelmann B. (2010) Digitale Medien in Schule und Unterricht Erfolgreich Implementieren. Eine Empirische Analyse aus Sicht der Schulentwicklungsforschung. Empirische Erziehungswissenschaft, Band 19. Waxmann, Münster.

Elliott J. (1991) Action Research for Educational Change. Open University Press, Milton Keynes, UK.

Elmore R.F. \& Burney D. (1999) Investing in teacher learning. In Teaching As the Learning Profession (eds L. DarlingHammond \& G. Sykes), pp. 236-291. Jossey-Bass, San Francisco, CA.

Erstad O. (2008) Changing assessment practices and the role of IT. In International Handbook of Information Technology in Primary and Secondary Education (eds J. Voogt \& G. Knezek), pp. 181-194. Springer, New York, NY.

Ertmer P.A. (2005) Teacher pedagogical beliefs: the final frontier in our quest for technology integration? Educational Technology Research and Development 53, 25-39.

Fraillon J. \& Ainley J. (2010) The IEA International Study of Computer and Information Literacy (ICILS). Australian Council for Educational Research, Australia. Available at: http://icils.acer.edu.au (last accessed 30 May 2010).

Geddis A.N., Lynch M.J. \& Speir S.B. (1998) Bridging theory and practice: towards a professional scholarship of pedagogy. Teaching and Teacher Education 14, 95-106.

Gibson I. (2008) Global partnerships. In International Handbook of Information Technology in Primary and Secondary Education (eds J. Voogt \& G. Knezek), pp. 833-844. Springer, New York, NY.

Goldsmiths (2009) E-scape Portfolio Assessment. Phase 3 Report. London: University of London. Available at: http:// www.gold.ac.uk/media/e-scape_phase3_report.pdf (last accessed 30 May 2010).

Joyce B. \& Showers B. (1995) Student Achievement through Staff Development: Fundamentals of School Renewal, 2nd edition. Longman, White Plains, NY.

Kennedy G., Judd T., Dalgarno B. \& Waycott J. (2010) Beyond natives and immigrants: exploring types of net generation students. Journal of Computer Assisted Learning 26, 332-343.

Knezek G.A. \& Christensen R. (2008) The importance of Information Technology attitudes and competencies in primary and secondary education. In International Handbook of Information Technology in Primary and Secondary Education (eds J. Voogt \& G. Knezek), pp. 321-331. Springer, New York, NY.

Koehler M. \& Mishra P. (2008) Introducing TPCK. In Handbook of Technological Pedagogical Content Knowledge (TPCK) for Educators (ed. AACTE Committee on Innovation and Technology), pp. 3-29. Routledge, New York, NY. 
Koehler M.J. \& Mishra P. (2005) What happens when teachers design educational technology? The development of technological pedagogical content knowledge. Journal of Educational Computing Research 32, 131-152.

Kozma R.B. (2008) Comparative analysis of policies for ICT in education. In International Handbook of Information Technology in Primary and Secondary Education (eds J. Voogt \& G. Knezek), pp. 1083-1096. Springer, New York, NY.

Law N. (2008) Teacher learning beyond knowledge for pedagogical innovations with ICT. In International Handbook of Information Technology in Primary and Secondary Education (eds J. Voogt \& G. Knezek), pp. 425-435. Springer, New York, NY.

Law N. (2009) Mathematics and science teachers pedagogical orientations and their use of ICT in teaching. Education and Information Technologies 14, 309-323.

Law N., Lee M.W. \& Chan A. (2010) Policy impacts on pedagogical practice and ICT use: an exploration of the results from SITES 2006. Journal of Computer Assisted Learning 26, 464-477.

Law N., Pelgrum W.J. \& Plomp T., eds (2008) Pedagogical practices and ICT use around the world: findings from the IEA international comparative study SITES2006. CERC Studies in comparative education. Hong Kong: Comparative Education Research Centre, The University of Hong Kong, and Dordrecht: Springer.

Levin B. (2004) Making research matter more. Education Policy Analysis Archives 12, 1-22.

Linn M.C. \& Hsi S. (2000) Computers, Teachers, Peers: Science Learning Partners. Lawrence Erlbaum Associates, Mahwah, NJ.

McLaughlin M. \& Talbert J. (2001) Professional Communities and the Work of High School Teaching. University of Chicago Press, Chicago, IL.

Moonen J. (2008) Evolution of IT and related educational policies in international organizations. In International Handbook of Information Technology in Primary and Secondary Education (eds J. Voogt \& G. Knezek), pp. 10711081. Springer, New York, NY.

Morales C. (2006) Cross-cultural validation of the will, skill, tool model of technology integration. Unpublished Doctoral Dissertation, University of North Texas, Denton, TX.

Newman D. \& Cole M. (2004) Can scientific research from the laboratory be of any use to teachers? Theory Into Practice 43, 260-267.

Niederhauser D.S. \& Stoddart T. (2001) Teachers' instructional perspectives and use of educational software. Teaching and Teacher Education 17, 15-31.

Norris C. \& Soloway E. (2008) An instructional model that exploits pervasive computing. In International Handbook of Information Technology in Primary and Secondary Education (eds J. Voogt \& G. Knezek), pp. 849-860. Springer, New York, NY.

Pelgrum W. (2009) Indicators of ICT in primary and secondary education. In Assessing the Effects of ICT in Education (eds F. Scheuermann \& F. Pedró), pp. 165-188. Publication Office of the European Union, Luxembourg.

Prensky M. (2001) Digital Natives, Digital Immigrants. Available at: http://www.marcprensky.com/writing/ Prensky\%20\%20Digital\%20Natives, \%20Digital\%20 Immigrants\%20-\%20Part1.pdf (last accessed 15 May 2010).

Quellmaz E.S. (2009) Assessing new technological literacies. In Assessing the Effects of ICT in Education (eds F. Scheuermann \& F. Pedró), pp. 121-142. Publication Office of the European Union, Luxembourg.

Reeves T. (2008) Evaluation of the design and development of IT tools in education. In International Handbook of Information Technology in Primary and Secondary Education (eds J. Voogt \& G. Knezek), pp. 1037-1051. Springer, New York, NY.

Resta P. \& Laferrière T. (2008) Issues and challenges related to digital equity. In International Handbook of Information Technology in Primary and Secondary Education (eds J. Voogt \& G. Knezek), pp. 765-778. Springer, New York, NY.

Riel M. \& Becker H.J. (2008) Characteristics of teacher leaders for Information and Communication Technology. In International Handbook of Information Technology in Primary and Secondary Education (eds J. Voogt \& G. Knezek), pp. 397-417. Springer, New York, NY.

Roy L., Chen H.-L., Cherian A. \& Tuiono T. (2008) The relationship of technology, culture and demography. In International Handbook of Information Technology in Primary and Secondary Education (eds J. Voogt \& G. Knezek), pp. 819-831. Springer, New York, NY.

Sandholtz J., Ringstaff C. \& Dwyer D.C. (1997) Teaching with Technology: Creating Student-Centered Classrooms. Teachers College Press, New York, NY.

Shulman L.S. (1987) Knowledge and teaching: foundations of the new reform. Harvard Educational Review 57, 1-22.

Somekh B. (2008) Factors affecting teachers' pedagogical adoption of ICT. In International Handbook of Information Technology in Primary and Secondary Education (eds J. Voogt \& G. Knezek), pp. 449-460. Springer, New York, NY.

Strudler N. \& Haerrington D. (2008) Quality support for ICT in schools. In International Handbook of Information Technology in Primary and Secondary Education (eds J. Voogt \& G. Knezek), pp. 579-596. Springer, New York, NY. 
Tilya F. (2008) IT and educational policy in the Sub-Saharan African region. In International Handbook of Information Technology in Primary and Secondary Education (eds J. Voogt \& G. Knezek), pp. 1145-1159. Springer, New York, NY.

Tondeur J., Hermans R., van Braak J. \& Valcke M. (2008) Exploring the link between teachers' educational belief profiles and different types of computer use in the classroom. Computers in Human Behavior 24, 25412553.

Van den Akker J., Gravemeijer K., McKenney S. \& Nieveen N., eds (2006) Educational Design Research. Routledge, London.

Venezky R.L. (2004) Technology in the classroom: steps toward a new vision. Education, Communication and Information 4, 3-21.

Voogt J. (2003) Consequences of ICT for aims, contents, processes and environments of learning. In Curriculum Landscapes and Trends (eds J. van den Akker, W. Kuiper \& U. Hameyer), pp. 217-236. Kluwer, Dordrecht.

Voogt J. (2008) IT and curriculum processes: dilemmas and challenges. In International Handbook of Information Technology in Primary and Secondary Education (eds J.
Voogt \& G. Knezek), pp. 117-132. Springer, New York, NY.

Voogt J. (2010) Teacher factors associated with innovative curriculum goals and pedagogical practices: differences between extensive and non-extensive ICT-using science teachers. Journal of Computer Assisted Learning 26, 453464.

Voogt J. \& Knezek G., eds (2008) International Handbook of Information Technology in Primary and Secondary Education. Springer, New York, NY.

Voogt J. \& Pareja Roblin N. (2010) 21st Century Skills. University of Twente, Enschede.

Voogt J. \& Pelgrum H. (2005) ICT and curriculum change. Human Technology: An Interdisciplinary Journal on Humans in ICT Environments 1, 157-175.

Voogt J., Fisser P. \& Tondeur J. (2010) Wat Weten We Over TPACK; Een Literatuurstudie Naar Technological Pedagogical Content Knowledge. University of Twente, Enschede.

Webb M. (2008) Impact of IT on science education. In International Handbook of Information Technology in Primary and Secondary Education (eds J. Voogt \& G. Knezek), pp. 133-148. Springer, New York, NY. 